Article

\title{
A Polycationic Brush Mediated Co-Delivery of Doxorubicin and Gene for Combination Therapy
}

\author{
Wenjuan Chen ${ }^{1}$, Mingming Zhang ${ }^{1, *}$, Wei Shen ${ }^{1}$, Bo Du ${ }^{1}$, Jing Yang ${ }^{1}$ and Qiqing Zhang ${ }^{1,2, *}$ \\ 1 Tianjin Key Laboratory of Biomedical Materials, Institute of Biomedical Engineering, Chinese Academy of \\ Medical Sciences \& Peking Union Medical College, Tianjin 300192, China; chenwenjuanvv@163.com (W.C.); \\ sw895971588@163.com (W.S.); dubojlu@163.com (B.D.); yangjing37@hotmail.com (J.Y.) \\ 2 Institute of Biomedical and Pharmaceutical Technology, Fuzhou University, Fuzhou 350002, China \\ * Correspondence: zhangmm@bme.cams.cn (M.Z.); zhangqiq@126.com (Q.Z.); \\ Tel.: +86-22-87890868 (M.Z. \& Q.Z.)
}

Received: 21 November 2018; Accepted: 27 December 2018; Published: 3 January 2019

\begin{abstract}
The combination of drug and gene strategies for cancer therapy, has exhibited greater effectiveness than drug or gene therapy alone. In this paper, a coil-comb shaped polycationic brush was used as a multifunctional carrier for co-delivery of drug and gene. The side chains of the comb block of the brush were composed of cyclodextrin (CD)-containing cationic star polymers, with a super-high density of positive charge. Doxorubicin (DOX) could be loaded into the cavity of CD polymers to form DOX-loaded nanoparticles (DOX-NPs) and the p53 gene could be subsequently condensed by DOX-NPs. The obtained DOX-NPs/pDNA complexes were less than $150 \mathrm{~nm}$ in size, and so could transport DOX and the gene into the same cell. The complexes performed well with regards to their transfection efficiency on MCF-7 cancer cells. As a result, enhanced cell growth inhibition, with decreased DOX dosage was achieved due to the synergistic effect of co-delivery of DOX and the p53 gene. This finding provides an efficient approach for the development of a co-delivery system in combination therapy.
\end{abstract}

Keywords: polycationic brush; co-delivery system; cyclodextrin polymer; combination therapy

\section{Introduction}

Co-delivery of biomolecules has wide applications in clinical diagnosis and treatment. For example, co-delivery of antigens and immune-stimulators can be more effective in activating immune responses and is of great value in cancer immunotherapy [1]. Moreover, co-delivery of contrast reagents and anti-tumor drugs can achieve cancer theranostics [2]. For gene therapy, combining drugs and genes strategies for cancer treatments has exhibited greater effectiveness compared with drug or gene therapy alone [3-7]. Due to the synergistic effect of the co-delivered drug and gene, decreased drug dosage, negligible side effects and high inhibition efficacy can be achieved [8,9]. Moreover, co-delivery of anti-tumor drugs and genes can also effectively prevent multidrug resistance of tumor cells [10]. The key point of synergistic therapy is to deliver drug and gene to the same cell and tissue. As a result, there has been increasing interest around the development of multifunctional delivery systems based on liposomes [11], cationic micelles [12-14], dendrimers [15], and inorganic nanoparticles [16]. Cyclodextrin (CD)-based polymers have been widely used in drug delivery systems since they provide the cavities for binding hydrophobic drugs. In gene delivery systems [17-21], CD mediated polycations are also able to enhance gene transfection efficiency due to CD features such as molecular inclusion, membrane disturbing and macromolecule shielding [22-24]. Combining the above advantages, co-delivery systems based on $\mathrm{CD}$ polymers have been developed. For example, cationic $\beta$-cyclodextrin-polyethylenimine-DOX (PC-DOX) conjugates for carrying a p53-encoding plasmid, 
promoted the inhibition of tumor growth in vivo and prolonged the survival time of tumor-bearing mice [25]. A bioreducible CD polymer system for co-delivery of paclitaxel and a p53 gene induced efficient cell apoptosis [26].

The essential challenge for gene carrier design is to achieve a high gene transfection efficiency. Studies showed that short-chain and hyperbranched polycations exhibited higher transfection efficiency and lower cytotoxicity, compared with linear ones with similar molecular weight $[27,28]$. Polymer brushes are a such kind of material, with ultra-high-density chains. They always stretch out from the surface because the distance between neighboring chains is lower than two-fold the gyration radius of a free polymer chain [29]. When polymerized using cationic monomers, the polycationic brushes usually exhibited excellent condensing capability compared to the anionic polymers, such as DNAs, proteins, etc. The colloidal stability of the formed particles was also enhanced due to the high osmotic repulsions between the brush chains. As a result, they exhibited higher transfection efficiency and lower cytotoxicities when used as gene carriers [30,31].

In our previous work [32], a well-defined coil-comb shaped polycationic brush with "CD-containing cationic star polymers" as side chains, was synthesized by atom transfer radical polymerization (Scheme 1). Benefiting from both brush-like structures and CD-based star polycations, the brush exhibited significantly enhanced gene transfection efficiency than the relevant single star polycation or PEI25K in normal cells (COS-7 and 293T cells). Considering that CD can further be used as a host to bind hydrophobic drugs via inclusion interactions, we attempted to use this brush to construct a multifunctional carrier for co-delivery of doxorubicin (DOX) and a p53-encoding plasmid (Scheme 1). Such nanocomplexes were employed for inducing an efficient cancer cell death by the synergistic effect of DOX and the expressed p53 protein.

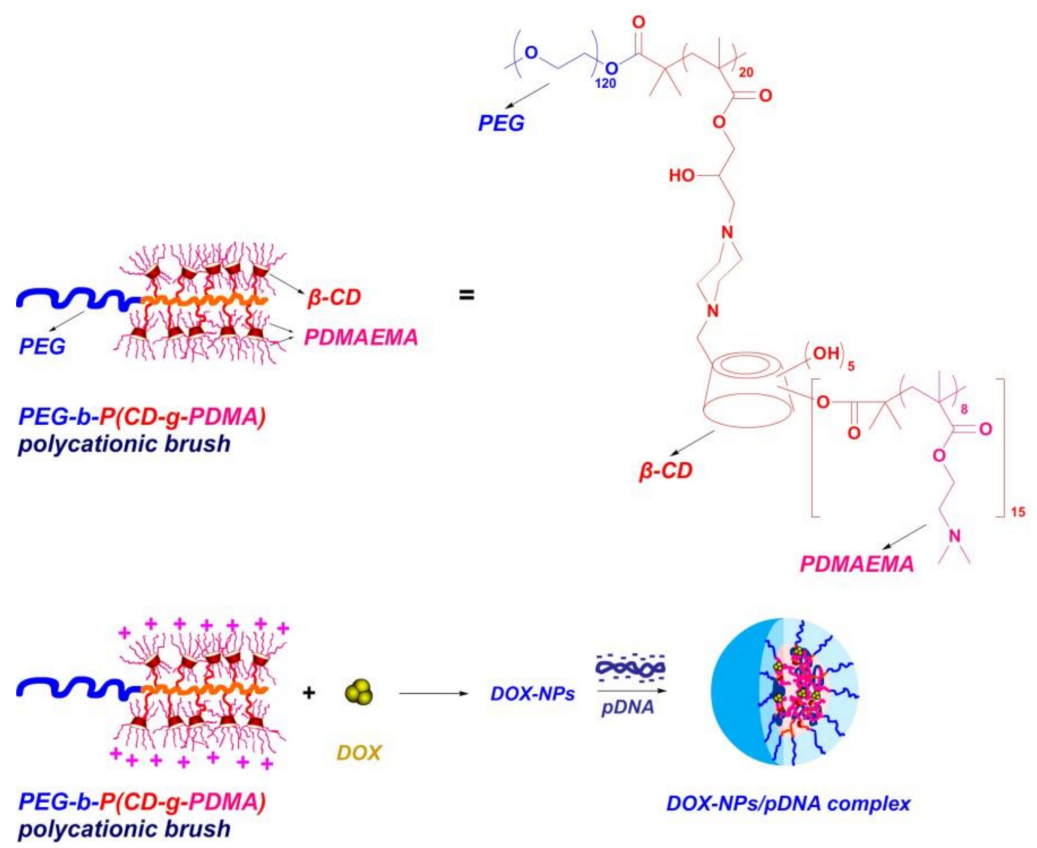

Scheme 1. Chemical structure of the polycationic brush, preparation of doxorubicin-loaded nanoparticles (DOX-NPs) and multifunctional DOX-NPs/pDNA complexes.

\section{Results and Discussion}

\subsection{Preparation of Polycationic Brush and Characterizatioin}

The polycationic brush was prepared according to our previous work [32]. In order to bind DOX more effectively, the degree of polymerization $\left(\mathrm{DP}_{\mathrm{n}}\right)$ of the $\mathrm{CD}$ monomer was increased to 20 in this study. Confirmed by the ${ }^{1} \mathrm{H}$ NMR result (Figure S1), the chain number of cationic 
poly(2-dimethylaminoethyl methacrylate) (PDMAEMA) was 15 per $\mathrm{CD}$ and the $\mathrm{DP}_{\mathrm{n}}$ of the DMAEMA monomer was 8 per chain. Thus, the molecular weight of the brush was calculated at about 423,600 , according to the above $\mathrm{DP}_{\mathrm{n}}$. The molecular weight distribution was then measured as 1.26 by gel permeation chromatography (GPC) (Figure S2).

\subsection{Preparation of DOX-NPs and Drug Release Behavior}

Driven by host-guest interactions between CDs on the brush and the hydrophobic DOX, DOX-loaded nanoparticles (DOX-NPs) were prepared. To obtain DOX-NPs with suitable physicochemical properties, different drug/polymer feed ratios were investigated and the characteristics of the nanoparticles are presented in Table 1. Both the loading content (LC) and the encapsulation efficiency (EE) increased with increasing drug/polymer feed ratio from $2 / 10$ to 5/10. Attributed to the shielding effect of the PEG outer corona, zeta potential values for all DOX-NPs fluctuated around zero (less than $10 \mathrm{mV}$ ). The hydrodynamic diameters $\left(D_{h} s\right)$ of all the samples were below $200 \mathrm{~nm}$, measured by dynamic laser scattering (DLS), demonstrating that they were appropriate for circulating in the body. However, only samples with a feed ratio of $2 / 10$ and $3 / 10$ showed relatively narrow size distribution. For further use, the DOX-NP with a drug/polymer feed ratio of 3/10 was selected as a representative formulation.

Table 1. Characteristics of DOX-NPs with different drug/polymer feed ratios.

\begin{tabular}{cccccc}
\hline $\begin{array}{c}\text { Feed Ratio } \\
\text { (Drug/Polymer, } \boldsymbol{w} / \boldsymbol{w})\end{array}$ & LC (\%) & EE (\%) & $\mathbf{D}_{\mathbf{h}}(\mathbf{n m})$ & PDI & $\begin{array}{c}\text { Zeta Potential } \\
(\mathbf{m V})\end{array}$ \\
\hline $2 / 10$ & $5.0 \pm 0.3$ & $22.1 \pm 1.0$ & $61 \pm 3$ & $0.24 \pm 0.02$ & $6.6 \pm 1.0$ \\
$3 / 10$ & $7.3 \pm 0.3$ & $23.0 \pm 0.9$ & $76 \pm 3$ & $0.38 \pm 0.04$ & $6.8 \pm 1.0$ \\
$5 / 10$ & $21.5 \pm 0.5$ & $45.2 \pm 1.0$ & $190 \pm 7$ & $0.69 \pm 0.04$ & $9.6 \pm 0.5$ \\
\hline
\end{tabular}

In vitro release of DOX from DOX-NPs was then investigated in phosphate buffer saline (PBS, $\mathrm{pH}$ 7.4) and acetate buffer saline (ABS, pH 5.0) solutions, respectively. As shown in Figure 1, the DOX release rate was faster at $\mathrm{pH} 5.0$ than 7.4. This is attributed to the following two factors. Firstly, the drug release rate was accelerated by the higher solubility of DOX in acidic solution than in neutral solution; secondly, DOX could be released more easily from the core due to the extension of the protonated PDMAEMA chains in the acidic condition. This is because PDMAEMA chains are $\mathrm{pH}$-sensitive with a $\mathrm{pK}_{\mathrm{a}}$ of about 7.1 [33]. This result indicates that DOX could be readily released via endosomal- $(\mathrm{pH}$ 5.5-6) or lysosomal-pH ( $\mathrm{pH} 4-5)$ in cells [34] and thus could induce antitumor activity.

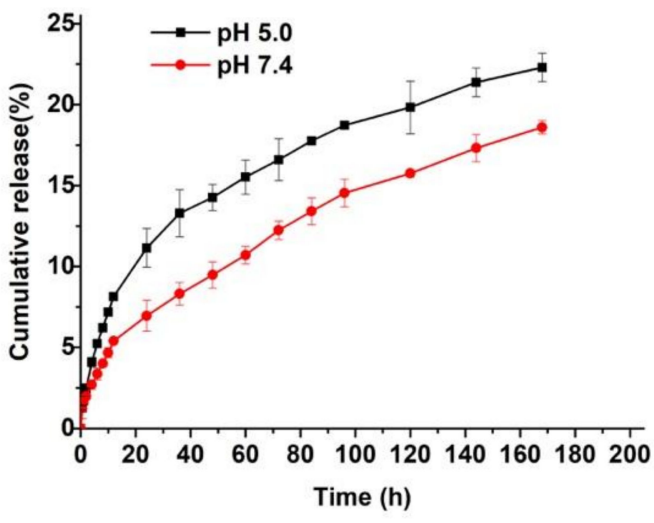

Figure 1. In vitro release profiles of DOX-NPs in PBS solution (pH 7.4) and acetate buffer saline (ABS) solution ( $\mathrm{pH}$ 5.0), respectively. 


\section{3. $p D N A$ Condensation and Characterization}

Next, a multifunctional delivery system was constructed using DOX-NPs as carriers to condense pDNA. The binding ability of DOX-NPs to pDNA was analyzed by agarose gel electrophoresis. Results in Figure 2 show that DOX-NPs entirely inhibited pDNA migration when the $w / w$ ratio was larger than 0.8. This demonstrates DOX-NPs exhibit good ability at condensing pDNA to form stable multifunctional complexes. The sizes of the complexes at various $w / w$ ratios were then measured by DLS. As shown in Figure 3, when the $w / w$ ratio is greater than 1, DOX-NPs efficiently compacted pDNA to form complexes with sizes less than $150 \mathrm{~nm}$, indicating they were able to deliver pDNA into cells. Typical AFM images of DOX-NPs/pDNA complexes ( $w / w$ ratio of 10$)$ showed that the complexes had an irregular spherical shape with a size less than $200 \mathrm{~nm}$ (Figure 4). This was smaller to the size of naked pDNA [35], indicating that pDNA was tightly condensed by the DOX-NPs.

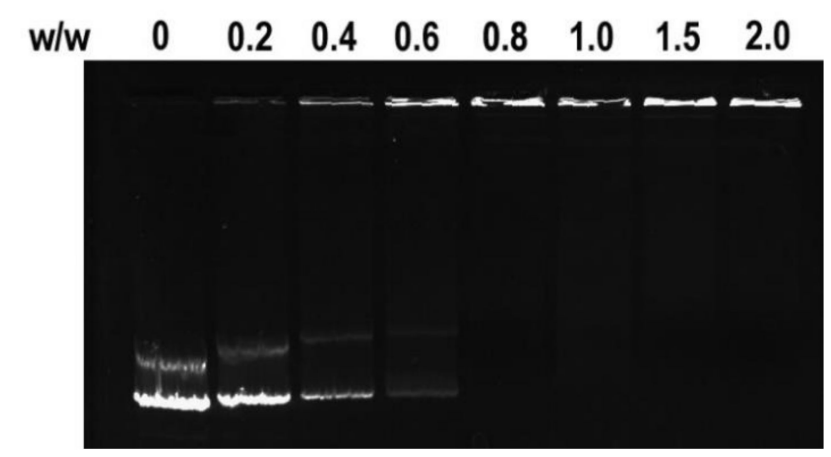

Figure 2. Agarose gel electrophoresis retardation assays of DOX-NPs/pDNA complexes at different $w / w$ ratios.

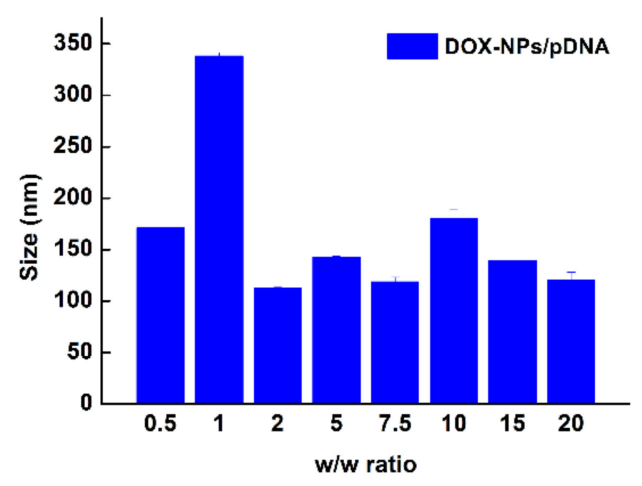

Figure 3. Particle size of DOX-NPs/pDNA complexes at different $w / w$ ratios.

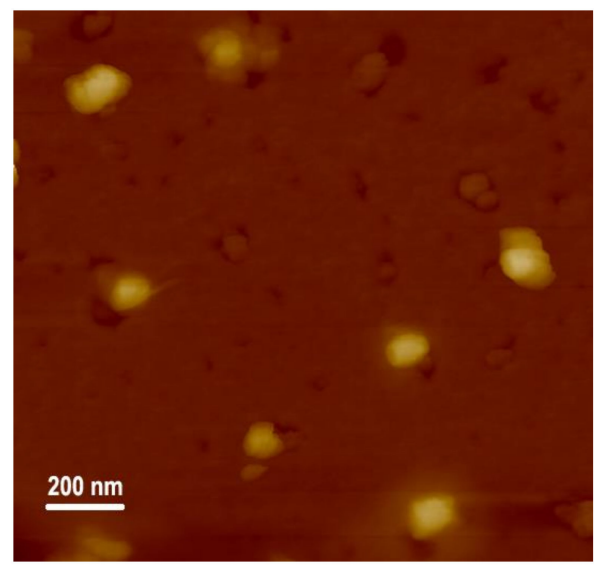

Figure 4. AFM image of DOX-NPs/pDNA complexes at optimal $w / w$ ratio of 10. 


\subsection{Co-Localization of Drug and Gene}

The key point of co-administration is to deliver the drug and gene into the same cell and then achieve a synergistic therapeutic effect. Herein, the DOX-NPs/pEGFP complexes mediated co-localization of DOX, and expressed EGFP in MCF-7 cells that was directly visualized under confocal microscopy. Since the sample was washed three times with PBS before observation, the appeared fluorescence in the image was inside the cells, rather than outside the cells. Moreover, since the MCF-7 cells were cultured as a monolayer on the substrate, the overlapped fluorescence should arise from the same cell, not multiple cells. As shown in Figure 5, significant green GFP and red DOX signals were observed in MCF-7 cells, and yellow signals, representing their overlap, were also found in these cells (Figure 5D, at the site pointed by the arrows; Figure 5E). However, due to the strong signal of expressed GFP, most of the DOX and DAPI signals were masked by the green GFP. Similar phenomena were also found in Zhang and Lin's studies [36,37]. To characterize the co-localization of gene and drug, the most used strategy is to stain both of gene and drug and observe their cellular uptake [38,39]. However, in our work, we directly observed the co-localization of the expressed protein and drug. This is more direct and precise than observation of cellular uptake of gene and drug. These results demonstrated that DOX-NPs/pEGFP complexes successfully transported DOX and pDNA into the same cell, and possessed high level of transfection capability.

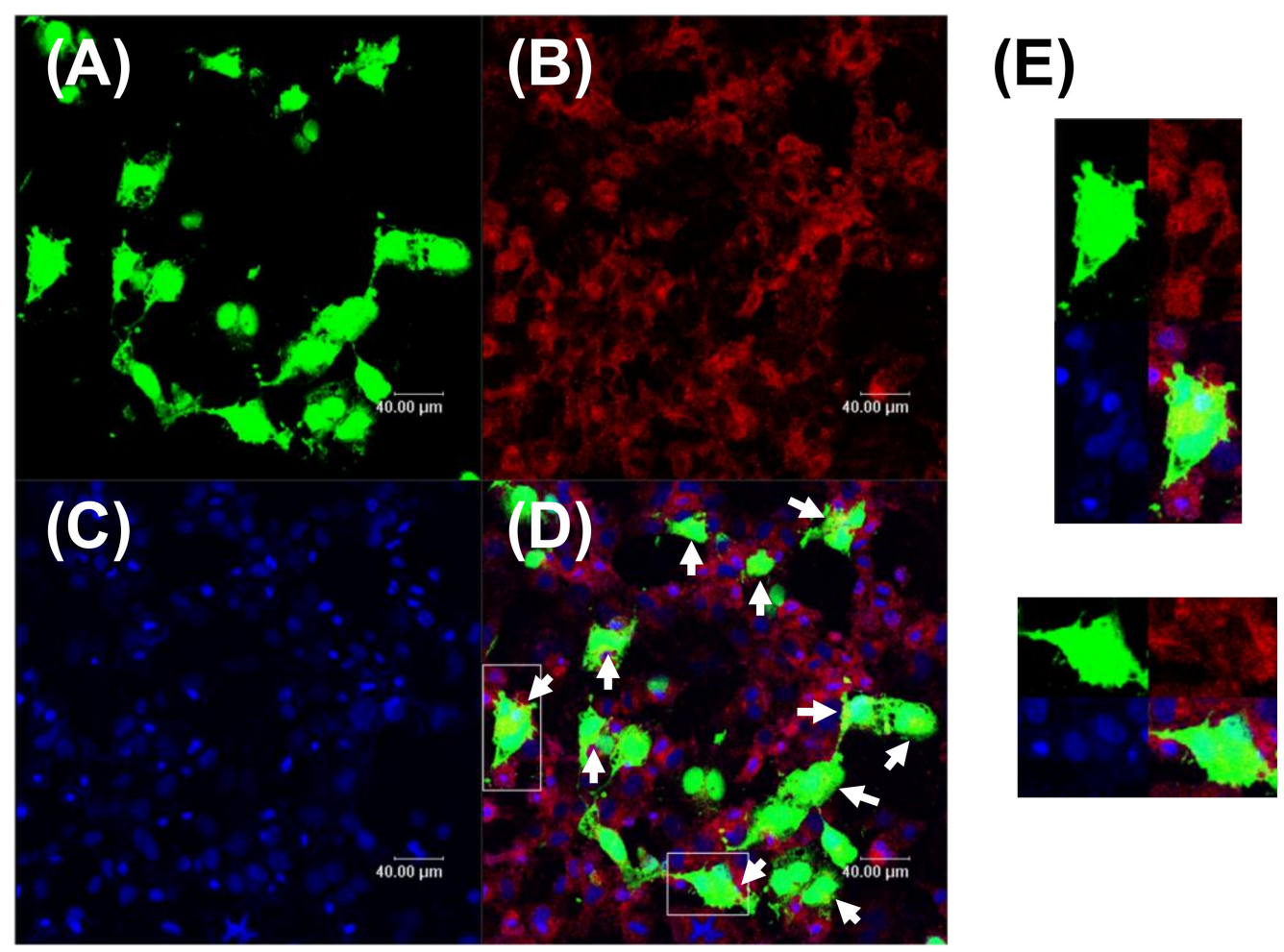

Figure 5. Confocal Laser Scanning Microscope (CLSM) images of MCF-7 cells transfected with DOX-NPs/pEGFP complexes at the optimal $w / w$ ratio of 10. (A) Expressed EGFP fluorescence (green); (B) DOX fluorescence (red); (C) cell nuclei stained by DAPI (blue); (D) merged image of (A-C); (E) magnifications of the image in the white box. Scale bars in all images represent $40 \mu \mathrm{m}$.

\subsection{Synergistic Anticancer Effect}

Based on the above co-delivery and transfection results, in vitro synergistic cancer therapeutic effects on MCF-7 cancer cells were then investigated by co-delivery of DOX and a p53-encoding plasmid. It is well known that $\mathrm{p} 53$ protein is a common tumor suppressor which has a pivotal role in cellular pathways, such as DNA repair, regulation of cell cycle, and cell apoptosis [40]. A mutant p53 gene loses the ability to control cell cycle and cell apoptosis, which results in tumor growth. 
Re-introduction of wild type p53 into tumor cells via effective carrier can re-stimulate cell apoptosis and then suppress cell proliferation. Moreover, stress signals in cells, such as DNA damage caused by drugs (e.g., DOX), can also induce a positive response of p53 [41], which would also contribute the inhibition of tumor growth. For this purpose, DOX-NP/p53 complexes were prepared, and their cytotoxicities on MCF-7 cancer cells were employed to evaluate the synergistic effect in vitro. Results in Figure 6A show the cytotoxicities of samples containing polycationic brushes (Brush, Brush/pEGFP, Brush/p53 and DOX-NPs/p53). As negative controls, the polycationic brush exhibited certain toxicity due to the positive charges of amino groups. When condensed with the pEGFP plasmid, the cytotoxicity of brush/pEGFP complexes decreased since the DNA neutralized some of the positive charges. However, when the p53 plasmid was introduced, the cell viability significantly decreased after incubated with brush/p53 complexes, which demonstrated the contribution of expressed p53 protein in cytotoxicity. Furthermore, when DOX and the p53 gene were simultaneously delivered to the same cell by DOX-NPs/p53 complexes, the cell growth was significantly inhibited compared to the ones with only p53 plasmid samples. Similar trends were also found in the samples that contained DOX. As shown in Figure 6B, at the same DOX concentration, DOX-NPs/pEGFP and DOX-NPs exhibited similar cytotoxicities towards MCF-7 cells, while the introduction of the p53 plasmid further decreased the cell viability. At $w / w$ ratio of 10 , the cell viability decreased to less than $30 \%$ after incubating with DOX-NPs / p53 complexes. However, when treated with only DOX, a greater DOX dosage was needed to achieve the similar antitumor effect. These results demonstrate that the polycationic brush could serve as an effective multifunctional carrier to load an appropriate dose of DOX and pDNA. They also show that synergistic anticancer effects with a lower DOX dosage can be achieved through co-delivery of DOX and a p53-encoding plasmid to the same cell. Generally, excessive chemotherapy would induce multi-drug resistance or enhanced toxicity and side effects [42]. Our results showed that the synergistic effect of DOX and the p53 gene decreased the DOX dosage and enhanced cell growth inhibition, which is beneficial to improve the quality of patient life. However, much remains to be investigated in the future. Different cells have different responses to the materials, the drugs and the genes, and these factors would influence the cellular uptake of the carriers, gene transfection efficiency and the synergistic effect of drugs and genes. Therefore, currently, many studies of co-delivery drug and gene from different groups focused on only one cell type [8,36,37,43,44]. It is somehow challenging to develop a co-delivery system that could work on more than one cell type. We consider that the mechanism of cell type dependence on the co-delivery system is worth conducting in detail, which would facilitate the development of broad-spectrum co-delivery systems.
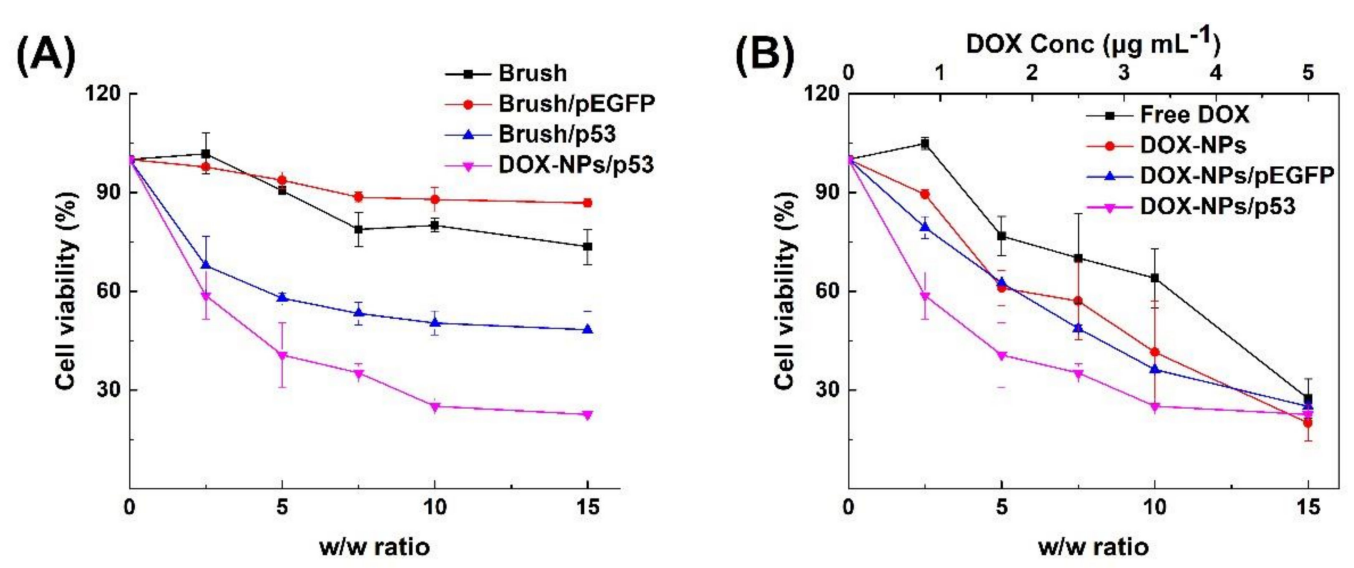

Figure 6. In vitro cytotoxicity against MCF-7 cells: (A) samples containing the polycationic brush (Brush, Brush/pEGFP, Brush/p53 and DOX-NPs/p53 complexes); and (B) samples containing DOX (free DOX, DOX-NPs, DOX-NPs/pEGFP and DOX-NPs/p53 complexes). 


\section{Conclusions}

In summary, a polycationic brush with "cyclodextrin-containing star polymers" as side chains was constructed to be a multifunctional carrier to co-deliver DOX and a gene. DOX-NPs were first prepared by host-guest interactions between CDs on the brush and hydrophobic DOX. A faster DOX release rate was achieved at $\mathrm{pH} 5.0$ than 7.4, demonstrating DOX-NPs were able to release payload under endosomal- or lysosomal-pH. At the same time, pDNA was well condensed by DOX-NPs to form DOX-NPs/pDNA complexes with a size less than $150 \mathrm{~nm}$. The complexes were able to transport DOX and a gene into the same cell, and had good transfection efficiency on MCF-7 cancer cells. As a result, enhanced cell growth inhibition with decreased DOX dosage was achieved due to the synergistic effect of co-delivery of DOX and a p53-encoding gene. This finding provides an efficient approach for the development of a co-delivery system in combination therapy.

Supplementary Materials: The following are available online at http://www.mdpi.com/2073-4360/11/1/60/s1, Materials and Methods, Figure S1: ${ }^{1} \mathrm{H}$ NMR spectrum of the polycationic brush, Figure S2: GPC spectrum of polycationic brush.

Author Contributions: Conceptualization, M.Z.; methodology, W.C. and W.S.; software, B.D.; validation, B.D.; investigation, W.C. and W.S.; resources, M.Z, J.Y. and Q.Z.; writing-original draft preparation, M.Z.; writing-review and editing, M.Z. and W.C.; project administration, M.Z., and Q.Z.; funding acquisition, M.Z. and J.Y.

Funding: This research was funded by Natural Science Foundation of Tianjin (17JCYBJC29100), National Natural Science Foundation of China (81501578 and 31771097) and CAMS Innovation Fund for Medical Sciences (2017-I2M-1-016).

Acknowledgments: This project was supported by Special Program for High-Tech Leader \& Team of Tianjin Government, Tianjin Innovation Promotion Plan Key Innovation Team of Immunoreactive Biomaterials.

Conflicts of Interest: The authors declare no conflicts of interest.

\section{References}

1. Neek, M.; Tucker, J.A.; Kim, T.I.; Molino, N.M.; Nelson, E.L.; Wang, S.-W. Co-delivery of human cancer-testis antigens with adjuvant in protein nanoparticles induces higher cell-mediated immune responses. Biomaterials 2018, 156, 194-203. [CrossRef] [PubMed]

2. Upponi, J.R.; Jerajani, K.; Nagesha, D.K.; Kulkarni, P.; Sridhar, S.; Ferris, C.; Torchilin, V.P. Polymeric micelles: Theranostic co-delivery system for poorly water-soluble drugs and contrast agents. Biomaterials 2018, 170, 26-36. [CrossRef] [PubMed]

3. Xiong, X.-B.; Falamarzian, A.; Garg, S.M.; Lavasanifar, A. Engineering of amphiphilic block copolymers for polymeric micellar drug and gene delivery. J. Control. Release 2011, 155, 248-261. [CrossRef] [PubMed]

4. Endres, T.K.; Beck-Broichsitter, M.; Samsonova, O.; Renette, T.; Kissel, T.H. Self-assembled biodegradable amphiphilic peg-pcl-lpei triblock copolymers at the borderline between micelles and nanoparticles designed for drug and gene delivery. Biomaterials 2011, 32, 7721-7731. [CrossRef] [PubMed]

5. Wang, H.; Zhao, Y.; Wu, Y.; Hu, Y.-1.; Nan, K.; Nie, G.; Chen, H. Enhanced anti-tumor efficacy by co-delivery of doxorubicin and paclitaxel with amphiphilic methoxy peg-plga copolymer nanoparticles. Biomaterials 2011, 32, 8281-8290. [CrossRef] [PubMed]

6. Wiradharma, N.; Tong, Y.W.; Yang, Y.-Y. Self-assembled oligopeptide nanostructures for co-delivery of drug and gene with synergistic therapeutic effect. Biomaterials 2009, 30, 3100-3109. [CrossRef] [PubMed]

7. Zhu, C.; Jung, S.; Luo, S.; Meng, F.; Zhu, X.; Park, T.G.; Zhong, Z. Co-delivery of sirna and paclitaxel into cancer cells by biodegradable cationic micelles based on pdmaema-pcl-pdmaema triblock copolymers. Biomaterials 2010, 31, 2408-2416. [CrossRef]

8. Sun, T.M.; Du, J.Z.; Yao, Y.D.; Mao, C.Q.; Dou, S.; Huang, S.Y.; Zhang, P.Z.; Leong, K.W.; Song, E.W.; Wang, J. Simultaneous delivery of sirna and paclitaxel via a "two-in-one" micelleplex promotes synergistic tumor suppression. ACS Nano 2011, 5, 1483-1494. [CrossRef]

9. MacDiarmid, J.A.; Amaro-Mugridge, N.B.; Madrid-Weiss, J.; Sedliarou, I.; Wetzel, S.; Kochar, K.; Brahmbhatt, V.N.; Phillips, L.; Pattison, S.T.; Petti, C.; et al. Sequential treatment of drug-resistant tumors with targeted minicells containing sirna or a cytotoxic drug. Nat. Biotechnol. 2009, 27, 643-651. [CrossRef] 
10. Li, Y.; Thambi, T.; Lee, D.S. Co-delivery of drugs and genes using polymeric nanoparticles for synergistic cancer therapeutic effects. Adv. Healthc. Mater. 2018, 7, 1700886. [CrossRef]

11. Wang, H.; Zhao, P.; Su, W.; Wang, S.; Liao, Z.; Niu, R.; Chang, J. Plga/polymeric liposome for targeted drug and gene co-delivery. Biomaterials 2010, 31, 8741-8748. [CrossRef] [PubMed]

12. Deng, J.; Gao, N.; Wang, Y.; Yi, H.; Fang, S.; Ma, Y.; Cai, L. Self-assembled cationic micelles based on peg-pll-plleu hybrid polypeptides as highly effective gene vectors. Biomacromolecules 2012, 13, 3795-3804. [CrossRef]

13. Qiu, L.Y.; Bae, Y.H. Self-assembled polyethylenimine-graft-poly( $\varepsilon$-caprolactone) micelles as potential dual carriers of genes and anticancer drugs. Biomaterials 2007, 28, 4132-4142. [CrossRef] [PubMed]

14. Sun, T.-M.; Du, J.-Z.; Yan, L.-F.; Mao, H.-Q.; Wang, J. Self-assembled biodegradable micellar nanoparticles of amphiphilic and cationic block copolymer for sirna delivery. Biomaterials 2008, 29, 4348-4355. [CrossRef] [PubMed]

15. Ma, D.; Zhang, H.-B.; Chen, Y.-Y.; Lin, J.-T.; Zhang, L.-M. New cyclodextrin derivative containing poly(1-lysine) dendrons for gene and drug co-delivery. J. Colloid Interface Sci. 2013, 405, 305-311. [CrossRef] [PubMed]

16. Meng, H.; Liong, M.; Xia, T.; Li, Z.; Ji, Z.; Zink, J.I.; Nel, A.E. Engineered design of mesoporous silica nanoparticles to deliver doxorubicin and p-glycoprotein sirna to overcome drug resistance in a cancer cell line. ACS Nano 2010, 4, 4539-4550. [CrossRef] [PubMed]

17. Xiu, K.M.; Yang, J.J.; Zhao, N.N.; Li, J.S.; Xu, F.J. Multiarm cationic star polymers by atom transfer radical polymerization from beta-cyclodextrin cores: Influence of arm number and length on gene delivery. Acta Biomater. 2013, 9, 4726-4733. [CrossRef]

18. Xu, F.J.; Zhang, Z.X.; Ping, Y.; Li, J.; Kang, E.T.; Neoh, K.G. Star-shaped cationic polymers by atom transfer radical polymerization from beta-cyclodextrin cores for nonviral gene delivery. Biomacromolecules 2009, 10, 285-293. [CrossRef]

19. Zhao, F.; Yin, H.; Zhang, Z.; Li, J. Folic acid modified cationic $\gamma$-cyclodextrin-oligoethylenimine star polymer with bioreducible disulfide linker for efficient targeted gene delivery. Biomacromolecules 2013, 14, 476-484. [CrossRef]

20. Hu, Y.; Yuan, W.; Zhao, N.-N.; Ma, J.; Yang, W.-T.; Xu, F.-J. Supramolecular pseudo-block gene carriers based on bioreducible star polycations. Biomaterials 2013, 34, 5411-5422. [CrossRef]

21. Choi, H.S.; Yamashita, A.; Ooya, T.; Yui, N.; Akita, H.; Kogure, K.; Ito, R.; Harashima, H. Sunflower-shaped cyclodextrin-conjugated poly(epsilon-lysine) polyplex as a controlled intracellular trafficking device. ChemBioChem 2005, 6, 1986-1990. [CrossRef] [PubMed]

22. Liao, Z.; Graham, D.; Hildreth, J. Lipid rafts and hiv pathogenesis: Virion-associated cholesterol is required for fusion and infection of susceptible cells. AIDS Res. Hum. Retrovir. 2003, 19, 675. [CrossRef]

23. Zidovetzki, R.; Levitan, I. Use of cyclodextrins to manipulate plasma membrane cholesterol content: Evidence, misconceptions and control strategies. Biochim. Biophys. Acta Biomembr. 2007, 1768, 1311-1324. [CrossRef] [PubMed]

24. Graham, D.; Chertova, E.; Hilburn, J.; Arthur, L.; Hildreth, J. Cholesterol depletion of hiv-1 and siv with beta-cyclodextrin inactivates and permeabilizes the virions: Evidence for virion-associated lipid rafts. J. Virol. 2003, 77, 8237-8248. [CrossRef]

25. Lu, X.; Wang, Q.-Q.; Xu, F.-J.; Tang, G.-P.; Yang, W.-T. A cationic prodrug/therapeutic gene nanocomplex for the synergistic treatment of tumors. Biomaterials 2011, 32, 4849-4856. [CrossRef] [PubMed]

26. Zhao, F.; Yin, H.; Li, J. Supramolecular self-assembly forming a multifunctional synergistic system for targeted co-delivery of gene and drug. Biomaterials 2014, 35, 1050-1062. [CrossRef]

27. Ping, Y.; Liu, C.-D.; Tang, G.-P.; Li, J.-S.; Li, J.; Yang, W.-T.; Xu, F.-J. Functionalization of chitosan via atom transfer radical polymerization for gene delivery. Adv. Funct. Mater. 2010, 20, 3106-3116. [CrossRef]

28. Wang, Z.H.; Li, W.B.; Ma, J.; Tang, G.P.; Yang, W.T.; Xu, F.J. Functionalized nonionic dextran backbones by atom transfer radical polymerization for efficient gene delivery. Macromolecules 2011, 44, 230-239. [CrossRef]

29. Li, L.; Hu, W.; Chi, L.; Fuchs, H. Polymer brush and inorganic oxide hybrid nanodielectrics for high performance organic transistors. J. Phys. Chem. B 2010, 114, 5315-5319. [CrossRef]

30. Jiang, R.; Lu, X.; Yang, M.; Deng, W.; Fan, Q.; Huang, W. Monodispersed brush-like conjugated polyelectrolyte nanoparticles with efficient and visualized sirna delivery for gene silencing. Biomacromolecules 2013, 14, 3643-3652. [CrossRef] 
31. Zhang, P.; Yang, J.; Li, W.; Wang, W.; Liu, C.; Griffith, M.; Liu, W. Cationic polymer brush grafted-nanodiamond via atom transfer radical polymerization for enhanced gene delivery and bioimaging. J. Mater. Chem. 2011, 21, 7755-7764. [CrossRef]

32. Zhang, M.; Xiong, Q.; Wang, Y.; Zhang, Z.; Shen, W.; Liu, L.; Wang, Q.; Zhang, Q. A well-defined coil-comb polycationic brush with "star polymers" as side chains for gene delivery. Polym. Chem. 2014, 5, 4670-4678. [CrossRef]

33. Zhao, Y.; Guo, K.; Wang, C.; Wang, L. Effect of inclusion complexation with cyclodextrin on the cloud point of poly (2-(dimethylamino) ethyl methacrylate) solution. Langmuir 2010, 26, 8966-8970. [CrossRef] [PubMed]

34. Klenchin, V.; Sukharev, S.; Serov, S.; Chernomordik, L.; YuA, C. Electrically induced DNA uptake by cells is a fast process involving DNA electrophoresis. Biophys. J. 1991, 60, 804. [CrossRef]

35. Barreto, J.A.; O’Malley, W.; Kubeil, M.; Graham, B.; Stephan, H.; Spiccia, L. Nanomaterials: Applications in cancer imaging and therapy. Adv. Mater. 2011, 23, H18-H40. [CrossRef] [PubMed]

36. Liu, C.; Liu, F.; Feng, L.; Li, M.; Zhang, J.; Zhang, N. The targeted co-delivery of DNA and doxorubicin to tumor cells via multifunctional pei-peg based nanoparticles. Biomaterials 2013, 34, 2547-2564. [CrossRef]

37. Wang, G.-H.; Cai, Y.-Y.; Du, J.-K.; Li, L.; Li, Q.; Yang, H.-K.; Lin, J.-T. Tat-conjugated chitosan cationic micelle for nuclear-targeted drug and gene co-delivery. Colloids Surf. B Biointerfaces 2018, 162, 326-334. [CrossRef] [PubMed]

38. Zheng, C.; Zheng, M.; Gong, P.; Deng, J.; Yi, H.; Zhang, P.; Zhang, Y.; Liu, P.; Ma, Y.; Cai, L. Polypeptide cationic micelles mediated co-delivery of docetaxel and sirna for synergistic tumor therapy. Biomaterials 2013, 34, 3431-3438. [CrossRef] [PubMed]

39. Han, K.; Chen, S.; Chen, W.-H.; Lei, Q.; Liu, Y.; Zhuo, R.-X.; Zhang, X.-Z. Synergistic gene and drug tumor therapy using a chimeric peptide. Biomaterials 2013, 34, 4680-4689. [CrossRef]

40. Yoshida, K.; Miki, Y. The cell death machinery governed by the p53 tumor suppressor in response to DNA damage. Cancer Sci. 2010, 101, 831-835. [CrossRef]

41. Fornari, F.A.; Jarvis, W.D.; Grant, S.; Orr, M.S.; Randolph, J.K.; White, F.K.H.; Gewirtz, D.A. Growth arrest and non-apoptotic cell death associated with the suppression of c-myc expression in mcf-7 breast tumor cells following acute exposure to doxorubicin. Biochem. Pharmacol. 1996, 51, 931-940. [CrossRef]

42. Ganta, S.; Devalapally, H.; Shahiwala, A.; Amiji, M. A review of stimuli-responsive nanocarriers for drug and gene delivery. J. Control. Release 2008, 126, 187-204. [CrossRef] [PubMed]

43. Liu, J.; He, J.; Zhang, M.; Xu, G.; Ni, P. A synergistic polyphosphoester-based co-delivery system of the anticancer drug doxorubicin and the tumor suppressor gene p53 for lung cancer therapy. J. Mater. Chem. B 2018, 6, 3262-3273. [CrossRef]

44. Skandrani, N.; Barras, A.; Legrand, D.; Gharbi, T.; Boulahdour, H.; Boukherroub, R. Lipid nanocapsules functionalized with polyethyleneimine for plasmid DNA and drug co-delivery and cell imaging. Nanoscale 2014, 6, 7379-7390. [CrossRef] [PubMed]

(C) 2019 by the authors. Licensee MDPI, Basel, Switzerland. This article is an open access article distributed under the terms and conditions of the Creative Commons Attribution (CC BY) license (http://creativecommons.org/licenses/by/4.0/). 